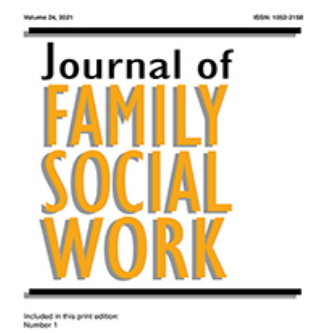

Journal of Family Social Work

Remente

ISSN: (Print) (Online) Journal homepage: https://www.tandfonline.com/loi/wfsw20

\title{
The challenges experienced by parents when parenting a child with hearing loss within a South African context
}

\section{Ronel Davids, Nicolette Roman \& Catherina Schenck}

To cite this article: Ronel Davids, Nicolette Roman \& Catherina Schenck (2021) The challenges experienced by parents when parenting a child with hearing loss within a South African context, Journal of Family Social Work, 24:1, 60-78, DOI: 10.1080/10522158.2020.1852639

To link to this article: https://doi.org/10.1080/10522158.2020.1852639

曲 Published online: 13 Jan 2021.

Submit your article to this journal $\widetilde{x}$

Џ Article views: 82

Q View related articles $₫$

View Crossmark data $ऍ$ 


\title{
The challenges experienced by parents when parenting a child with hearing loss within a South African context
}

\author{
Ronel Davids, Nicolette Roman, and Catherina Schenck \\ Faculty of Community and Health Sciences, Social Work, University of the Western Cape, Cape Town, \\ South Africa
}

\begin{abstract}
The purpose of the current study was to explore the challenges experienced by hearing parents when parenting a child with hearing loss. Using a qualitative purposive sampling design, interviews were conducted with 13 parents ( 9 mothers, 4 fathers) residing in Cape Town, South Africa. Four salient themes emerged, namely: 1) communication is difficult, hard, and frustrating; 2) lack of knowledge and information about hearing loss makes it difficult to parent; 3 ) little or no support makes for a lonely journey; and 4) support identified by parents for parents. The findings of the study have important implications for collaboration and partnerships between parents and health and family practitioners within South Africa for the design and development of supportive interventions for parents parenting a child with hearing loss.
\end{abstract}

\section{ARTICLE HISTORY}

Received 17 October 2019

Revised 5 October 2020

Accepted 26 October 2020

\section{KEYWORDS}

Hearing parents; a child with a hearing loss; challenges; experiences

\section{Introduction}

In South African, the healthcare infrastructure is thought to be reasonable in terms of its development when compared to other African countries (Ramma \& Sebothoma, 2016). Although there is no national consensus on the statistic in relation to how many hearing parents have children with hearing loss in South Africa, the prevalence of hearing loss among children is four to six in every 1,000 infants in the public healthcare sector (Swanepoel et al., 2009). Prevalence of hearing loss in the Cape Town Metropolitan area, the geographical location of this study, found that $11.4 \%$ of 174 children aged $0-3$ years and $4.3 \%$ of 430 children aged $4-9$ years presented with hearing loss (Ramma \& Sebothoma, 2016). Ninety percent of children born with a hearing loss are born to hearing parents (Cole \& Flexer, 2015) who often know nothing or very little about the phenomenon (Kushalnagar et al., 2011). In addition, the literature indicates that these parents experience a number of unique challenges when parenting a child with hearing loss, including communication, emotional well-being, and social support challenges (Kobosko \& Zalewska, 2011; Szarkowski \& Brice, 2016).

CONTACT Ronel Davids rsdavids@uwc.ac.za E Faculty of Community and Health Sciences, Social Work, University of the Western Cape, Cape Town, South Africa.

(c) 2021 Taylor \& Francis Group, LLC 
There is a paucity of research on the challenges and needs of parents parenting children with a hearing loss in South Africa, with most of the available literature on the topic advocating for infants by focusing on intervention and early hearing detection (Swanepoel \& Storbeck, 2008) and infant hearing loss or maternal views on infant hearing loss (Storbeck, 2012). This research, therefore, identifies a gap in the literature on the challenges that contribute to the experiences of hearing parents parenting a child with hearing loss. Based on our review to date, we have found only two reported intervention and support programs for parents in South Africa. One of these support programs for parents are offered and facilitated by an organization known as "Thrive." Thrive is a parent support and advocacy group that provides early family intervention for parents of children with hearing loss in South Africa. Their parent mentorship program is offered by parents who have accepted their parenting journey, and who - with an unbiased approached - can walk alongside other parents on their journey of parenting a child with hearing loss. A further intervention program known as "HI HOPES" (an acronym which stands for Home Intervention Hearing and language Opportunities Parent Education Services), offers parents and families weekly home-based support that is both child-centered and family-directed. This program was initiated due to the lack of support for families of infants with a hearing loss in South Africa. However, these programs are only offered in certain parts of the country so the need for similar programs in other parts has become apparent.

Given the importance of the parent-child relationship, a better understanding of the challenges experienced by parents parenting children with a hearing loss is needed. Exploring some of the challenges that shape these parents' parenting experiences is a valuable step in the process of building knowledge. These insights can provide much needed support for parents and families, with the intention of growing knowledge and providing intervention in the emerging field of social work and disability. Parenting a child with a hearing loss presents unique challenges for hearing parents in that parenting a child with a hearing loss is very demanding and places an extra strain on parents, seriously influencing the quality of the parent-child relationship and family acclimatization to the child's hearing loss and how the family copes with the disability (Calderon, 2000). A number of studies have highlighted parents' need for: (1) support and participation in parent-to-parent networks (Jackson et al., 2008);(2) unbiased assistance with communication options; and (3) multifarious information (Jamieson et al., 2011).

\section{Challenges experienced by parents}

Firstly, research shows that strong social support can act as a protective mechanism against parent stress, provide emotional support, and positively contribute to the coping and well-being of hearing parents of children with hearing loss (Asberg et al., 2008; Zaidman-Zait, 2007). Studies have attested to strong social 
support from family members and close friends who have assisted parents to mitigate the negative effects of parenting a child with hearing loss. Parents with strong social support are able to manage challenges more effectively compared to parents with few supports (Dunst \& Trivette, 1994). The findings of the study by Asberg et al. (2008) substantiated that support can provide parents with significant life satisfaction as well as lower levels of stress when parenting a child with hearing loss. Their cross-sectional quantitative study indicated that handling their children's emotions and behaviors was a stressful experience for them.

Further research highlight parents' need for additional support to connect and have discussions with other parents who are also parenting children with a hearing loss (Jackson, 2011). Jackson et al. (2010) examined parents' perceptions of their quality of life after their child was identified with hearing loss. They found that only one-third of their study's participants reported participating in any kind of parent support group. Descriptive analysis implied lower satisfaction ratings in the area of emotional well-being, with families reporting their child's hearing loss as having the biggest impact on their emotional well-being.

Over the years there has been a growing body of evidence showing that parent-to-parent support provides positive assistance in managing the needs of parents (McHugh et al., 2013; Olin et al., 2014). In a study conducted by Jackson (2011), 456 respondents valued the importance of social-emotional support together with support in the form of informational resources and educational advocacy. Written responses to a research questionnaire showed that parents sought additional opportunities to connect with mentors, role models, and other parents. Another study by Jackson et al. (2008) indicated parents' need to frequently talk to someone - someone they can identify with regarding their experiences, and who can act as parent mentors to better meet their needs - both personally and emotionally, through the mentoring relationship. Friedman Narr and Kemmery (2015) study correlated with Jackson et al.'s (2008) study when they used a qualitative design to explore parents' mentor conversations with individual families of children with a hearing loss receiving parent-to-parent support as part of a family support project. Their study was able to show that many of the conversations parent mentors had with parents consisted of providing support to parents and that parent-toparent support was significantly important.

Secondly, parents have identified and described communication difficulties as one of the main challenges contributing to the experiences of parenting a child with hearing loss (Zaidman-Zait \& Most, 2005). The study by Humphries et al. (2019) on parental support identified common questions regarding communication challenges posed by parents. Although the answers to these questions were intended to assist professionals as they are at the forefront of advising and counseling parents, these questions serve as an important source of information for parents who have similar questions. However, regardless of the mode of communication parents adopt, a child with a hearing loss presents unique 
communication challenges for hearing parents (West, 2012). In that, replacing learned communication practices with new approaches can be challenging. Learning a new language as an adult can be time-consuming as well as challenge a parent's sense of competence (McKee, 2006). For these reasons, parents have often described communication as frustrating, difficult, and demanding, causing ineffective communication, and a strain on parent-child interactions (Freeman et al., 2002). Disruption in the interaction between the parents and child affects parenting roles and responsibilities negatively if there is difficulty in adopting new approaches to meeting the communication needs of a child (TamisLeMonda et al., 2002). Parents who struggle to adjust to the communication needs of their child from an early age may find it difficult to communicate with the child as he/she grows older (Quittner et al., 2010). In reflecting on the typical communication of a child with a hearing loss using sign language in the everyday South African context, and being born into a family with no prior experience of sign language, Blose and Joseph (2017) made the following observations. Their study showed that there was a gap in the communication mode at home, and described communication interaction between parent and child as limited, poor, mainly oral, and with constant breakdowns. The conclusion drawn by the study was that communication at home between parents and a child with a hearing loss was problematic. Joseph and Alant (2000) study on parentchild interaction revealed inadequate communication between parents and their children who use sign language in South Africa. The study implemented a descriptive survey design to obtain information on the signing practice of mothers, and found mothers' signing skills to be inadequate, using speech and simultaneous communication (speaking and signing at the same time) more often.

On the other hand, studies describing the perceptions of the communication experiences of adults with a hearing loss growing up in hearing families found that deaf adults reported having limited access to contextual learning opportunities in families while growing up. These contextual learning opportunities were non-existent for children with a hearing loss in conversations at family mealtimes and family outings, for example, as parents were unable to communicate with their children in sign language (Hall et al., 2019). A study conducted in Cyprus by Hadjikakou and Nikolaraozi (2008) showed similar results. Interviews were conducted with 24 adults with a hearing loss between the ages of 19 to 54 years with different family and school backgrounds. They found that from an early age, these adults experienced negative communication at home and could not communicate orally or in sign language with their parents. The study recommended that regardless of the modality of communication between parent and child, early and mutual modes of communication between family and child should be encouraged, thus ensuring amiable family communication interchanges and experiences. 
Thirdly, the provision of information can build parents' confidence and sensitivity in their parenting practices toward their child and in their ability to raise and parent a child with hearing loss (Bemrose, 2003). However, a study conducted by Jamieson et al. (2011) on the support needs of parents found little documented about the need for information, support, and guidance for parents of children with hearing loss. The findings of their study identified four areas of concern for parents; namely, parents' need for various types of information, including the need to know how their child develops; parents' need for a family-centered approach to service provision; parents' apprehension about education and future opportunities of their child; and parents' concern about parenting children with hearing loss with additional needs.

In a study conducted by A. M. Young (2003) observed that parents found it difficult to access information, which impacted considerably on their experiences of parenting. The study recommended that parents be provided with information on parenting a child with hearing loss during the early stages of their life, so that by the time the child reaches adolescence, parents may be viewed as experts who then, in turn, could provide parenting information and support to other parents in a similar situation.

Gilliver et al. (2013) examined parents' recollections of and experiences with a child diagnosed with hearing loss, and found that parents desire for information to be tailored to their individual needs. This suggests that parent's require more information to meet their specific parenting needs as their child grows older. The varied demand put on parents coupled with not knowing anything about hearing loss, leaves parents highly dependent on professionals for information. Narratives in this study showed parents practical and emotional challenges experienced by parents and their need for information when parenting a child with a hearing loss.

When information on parenting is reliable and accurate, it can contribute to parents' ability to cope and can assist in the decision-making process, so that parents can become active in their role in child management (Young et al., 2005; Zaidman-Zait \& Jamieson, 2004). Henderson's (2015, p. 38) study on the conceptual framework on parent-to-parent support for parents of children with hearing loss, provided evidence of 29 research studies indicating that parents would benefit from information that is "accurate, well-balanced, comprehensive, and conveyed in an unbiased manner." This study further indicated that parents had received inadequate, out-dated, biased, and incomplete information from their child's specialists.

Research also shows that families are turning to the Internet to access information about hearing loss. The Internet allows parents to gain information quickly, easily, and conveniently in the privacy of their own home, and can assist parents in making informed decisions (Porter \& Edirippulige, 2007). A study conducted in Australia by Porter and Edirippulige on parents seeking hearing loss-related information on the Internet confirmed that parents 
continue to search for information on the Internet throughout the lifespan of their child and are likely to participate in online support groups. However, the authors observed that the information on some topics seen as very important to parents of children with a hearing loss, such as communication choices, was either limited or unavailable on the Internet. They recommended that service providers make an effort to understand the unique needs of parents, adapt their information provision accordingly, and ensure that online information is not only relevant, but also meaningful and accessible to assist parents in making informed child care decisions.

Therefore, the aim of the current study is to explore the challenges experienced by hearing parents when parenting a child with hearing loss. The study will help to increase our understanding of parents' experiences, and subsequently improve intervention programs.

\section{Method}

\section{Study setting}

The research study was conducted in Cape Town, South Africa. Cape Town is the second most populous city in South Africa and is ranked as the tenth most populous city in Africa (UN-Habitat, 2014). Locally, it is known as "the Mother City." The ethnic and racial composition of Cape Town is made up of $42.4 \%$ Colored (mixed race), 38.6\% Black African, $15.7 \%$ White, $1.4 \%$ Asian or Indian, and $1.9 \%$ other (Statistics South Africa, 2012).

\section{Study design and participants}

A qualitative research approach with an explorative design was implemented, as the focus was on exploring and describing the challenges of parents when parenting their children with hearing loss. The challenges experienced by parents were viewed as the central phenomenon requiring exploration and understanding, as qualitative research aims to provide an in-depth understanding of the social world of the participants by learning about their experiences and perspectives (Ritchie \& Lewis, 2003). Therefore, our study provides an understanding of how hearing parents experience and interpret these challenges when parenting a child with hearing loss. Purposive sampling was used to select the participants for the study. Participants were recruited using two techniques: (1) approaching three local organizations of the deaf to assist with providing names of parents who attended their parenting programs; and (2) the participant referral snowballing technique, whereby participants knew of other parents that may be interested in participating in the research study and that had a similar experience to theirs (Babbie, 2010). 
The population for the study was hearing parents of children with a hearing loss from different cultural backgrounds. A total of 13 parents between the ages of 35-55 years participated in the research. Participants consisted of nine (9) hearing mothers, and four (4) hearing fathers of a child with hearing loss between the ages of 10 and 16 . Originally, 15 parents agreed to participate, but later two fathers declined participation, citing work commitments as their reason for withdrawal. None of the participants were related. Two (2) of the hearing parents had attended university, while three (3) parents had attended college. Five (5) of the parents matriculated, and three (3) had left school without passing matric. All the participants were employed, except for one mother who receives a government social support grant (Table 1: Demographics of participants).

Table 1 below reflects the demographic profile of the hearing parents regarding their parent experiences when parenting a child with hearing loss.

\section{Data collection}

Data were collected via semi-structured interviews with the aim of understanding the social support needs and challenges from the perspectives of the parents. Written informed consent was obtained from all the participants prior to conducting the study. Participation was also voluntary. The following interview questions, which focused on the challenges of parents, were asked: (1) Tell me about your experience of parenting a child with hearing loss; tell me about the challenges you experience when parenting your child with a hearing loss; (2) Tell me how these challenges affect your experience as a parent of a child with hearing loss; and (3) What kind of support do you think parents need to assist them in their parenting role when parenting a child with a hearing loss?

Ethical clearance was obtained from the University of the Western Cape's Senate Research Committee before the research commenced. All ethical considerations were adhered to, including confidentiality and anonymity of participants.

\section{Data analysis}

Data analysis took place according to Klenke's (2008, p. 231) suggested steps. This entailed searching for themes that could be "validated by the re-emerging and repetition of specific ideas" (Klenke, 2008, p. 231); and clustering of data according to themes, which were then sorted into sub-themes to give a descriptive representation of the phenomenon. The data were sent to an independent coder to improve the coding in the qualitative data analysis and for verification of themes and sub-themes. The use of an independent coder assisted with the transparency and conformability of the coding process, 


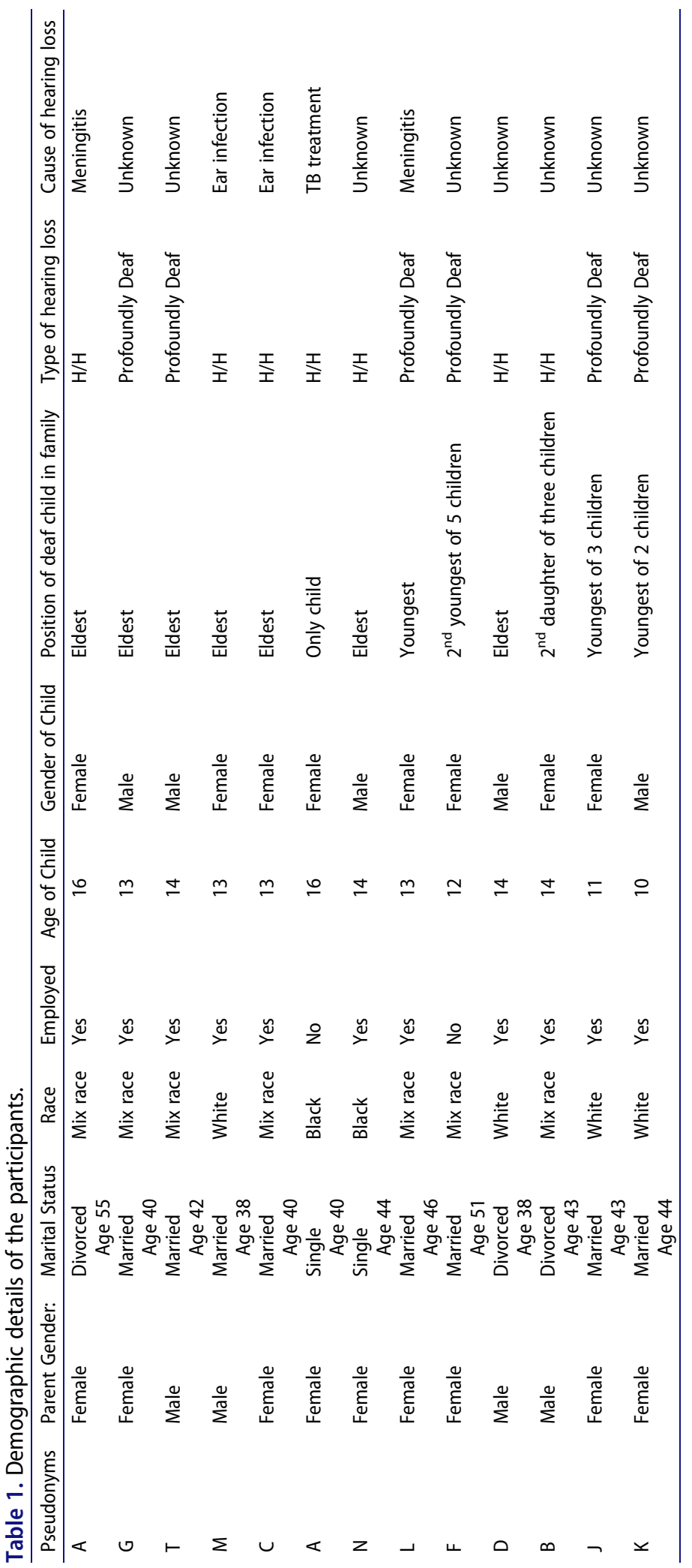


promoting trustworthiness of the data analysis (O'Connor \& Joffe, 2020). Conformability means that the data accurately represent the information that the participants provided and that the interpretations of the data are not invented by the researcher (Polit \& Beck, 2012).

\section{Results}

Four major themes emerged from the data analysis, namely: (1) communication is difficult, hard, and frustrating; (2) the lack of knowledge and information about hearing loss makes it difficult to parent; (3) the lack of support for parents makes it hard to parent a child with hearing loss; and 4) description of support as described by parents for parents.

\section{Theme 1: Communication is difficult, hard and frustrating}

Five parents cited communication as the main challenge between themselves and their child with a hearing loss. Parents described how communication challenges affected their parenting, causing feelings of frustration and guilt. They found it hard to explain and did not always know how to communicate with their child. The following quotes from parents illustrate their communication difficulties: "It is so frustrating to communicate with her"; "Communication is really challenging"; "The communication is a big problem with us"; "It is hard to explain it to her"; I do not always know how to communicate with her."

Five parents reported that communication and learning sign language was challenging and difficult to learn, affecting their parenting roles and responsibilities negatively: "I don't know sign language and I don't know how to explain things to him/her." One mother described her day-to-day communication with her child as poor, with little substance. Often the conversations were limited to "yes" or "no" responses: "It is also about the day to day communication, the sign that we don't know"; "I cannot explain things to her"; "All she says is 'yes' or 'no' and it has no relevance to the conversation". Parents' inability to communicate with their child also affected their ability to discipline their child, causing frustration, as described by one parent: "It's all about communication, it makes disciplining her very frustrating and difficult."

One parent reported how she and her child have been living past each other due to communication challenges: "Communication is difficult, we live so past each other."

Three parents felt guilty and ashamed, as they experienced communication difficulties in sharing their family ideologies, such as family culture and family religion with their children. They described their experience as follows: "How do I explain our culture to her, I feel ashamed that I can't communicate it to her"; "He doesn't know our way of life, the school he goes is different to our faith"; "I feel so guilty, how do I communicate this (our way of life) to him." 


\section{Theme 2: Lack of information about hearing loss makes it difficult to parent}

Participants reported lacking information and understanding about their child's hearing loss in general. They explained that they had very little knowledge and specific information pertaining to their child's hearing loss which made parenting difficult. Examples of these descriptions are as follows: "Her deafness is the major issue, not knowing anything about it"; "Not knowing about deafness and her own deafness"; "Basically, I know nothing about deafness and this makes parenting difficult." One parent felt that parents should be provided with information from the onset of the diagnosis, which could contribute to better understanding, resulting in easier parenting: "If we are told from the start what this journey will be all about, then maybe it would make parenting easier." Most parents did not know the cause or have any information on the etiology of their child's hearing loss, often stating during our interviews that "No one in the family is deaf." One parent commented that they wanted specific information on how their child became deaf, which could have eased their parenting experiences and helped them with their parenting "All of this information on how she became deaf is important, it will help to be better parents." Two fathers in particular experienced difficulty in attending any support programs due to their working hours and found accessing information about hearing loss on the Internet easier. They expressed the need for new online applications to assist parents in obtaining information: "I go online sometimes for information to learn about my child's hearing loss, as I don't have time for these meetings due to work commitments ... "They need to develop new Google apps for parents so we can access information, for example, on communication, as I don't really have time."

\section{Theme 3: Little or no support makes a lonely journey}

Some parents reported feeling ostracized by family members and blamed for their child's hearing loss, leading to feelings of isolation and loneliness. Two parents commented on the negative attitudes of their family members who openly denied their child with a hearing loss because hearing loss was never experienced in their family: "Family members are nasty and don't accept him because he can't hear"; "In my family, my mother chased me away and she said that the child can't be using hearing aids because that has never happened in the family." Another mother described how her son's father did not accept him, based on his belief that deafness is not hereditary in his family: "He (father) said it's not his child as he said in the family we don't have things (hearing loss) like this."

Four mothers stated that they felt alone and isolated with very little support from friends, the community, family members, or even professionals, making 
parenting a child with a hearing loss more difficult, as is evident in the following quotes: "I feel isolated as a parent"; "I was alone for years, I had to walk this road alone"; "There was no support"; "Sometimes I feel alone in doing all of this";. "The thing is, we as parents don't have much support"; "There is no community support, no family support, no one to assist each other"; "There is no help from professionals who knows about deafness".

\section{Theme 4: Support identified by parents for parents}

A fourth theme that emerged were recommendations by parents for support to minimize their adverse experiences related to parenting a child with hearing loss. Parents all agreed that a support group would minimize feelings of isolation and afford them opportunities to share and learn from each other's experiences. This was evident in the few excerpts below: "Support ... then parents don't need to experience everything alone"; "As parents we need support groups, we can learn from each other and talk about our experiences"; "Parents can come together to share." All four fathers stated that there should be support groups for mothers, with one father suggesting a social media (WhatsApp) support group, especially for mothers, if distance or access to support groups presented a problem. Another father suggested a social media (WhatsApp) support group for mothers with a social worker. These sentiments are encapsulated in the following excerpts: "A mother support group on the phone, then they don't need to experience everything alone"; "Supportive group on WhatsApp"; "A WhatsApp group with a social worker"; "What about a WhatsApp group for mothers to support mothers if they live far?" Another parent suggested the need for counseling for parents and for their child with a hearing loss, while another stated that they needed support with communicating with their child, as they felt isolated from their child with a hearing loss: "There is no counseling for deaf children and us, we need it ... we need support with communicating with our children as we feel isolated from them".

\section{Discussion}

The aim of the current study was to explore the challenges experienced by hearing parents when parenting a child with hearing loss in South Africa. The analysis of the responses provided by the parents generated four themes. These themes describe the practicalities of parents' communication challenges; their lack of knowledge, information, and support; and provides a description of what kind of support parents would like to receive when parenting a child with hearing loss.

The findings in the current study are consistent with previous research conducted by Freeman et al. (2002) and Hintermair (2000) who reported that daily interaction involving communication between parents and a child with 
hearing loss leads to frustration, communication difficulties, and negative relations. The findings are also consistent with those reported by Peterson (2001) and Marschark (2007), as they show parents experiencing difficulties in learning sign language to improve communication interaction with their child with a hearing loss, which could lessen feelings of guilt and shame experienced by parents. Our study shows parents' inability to communicate with their children, leaving them feeling guilty and ashamed. Feelings of guilt and shame may in turn result in feelings of insecurity about their lack of skills to communicate effectively with their child, which may have far-reaching implications for effective parenting (Mason \& Mason, 2007).

Our findings were able to show parents' desire to communicate and share their family ideologies, such as family religious practices and family culture with their child with a hearing loss. These ideologies are normally passed down from generation to generation, but may exclude a deaf child due to communication difficulties. Ideology speaks to a family's cultural identity, as described by A. Young (2002, p. 6), specifically referring to a family's "preferred language, value systems, religious affiliations, class background, and socioeconomic status." Often children with hearing loss adopt a new language and culture that is outside the context of family norms, especially when they are attending and boarding at schools for the deaf. The findings would suggest that the separation of the two worlds is further widened as communication difficulties makes it harder for these two worlds to be understood (Munoz-Baell \& Ruiz, 2000).

The need for diverse information about hearing loss to assist in making good decisions on behalf of their children and to parent effectively, was also singled out as a challenge for parents, contrary to the abundance of information and knowledge available for parents and professionals to make effective choices for their child with a hearing loss (DesJardin, 2016). The findings of the current study highlight parents lack of information, lack of knowledge, and lack of understanding about their child's hearing loss, making their parenting experience hard and difficult. The literature also suggests that parents may present information-seeking behavior and struggle if there is no definitive cause to attribute to their child's hearing loss (Parker et al., 2000; Steinberg et al., 2007). Our study is therefore consistent with the findings of Henderson's (2015) study which postulates that parents would benefit from information that is comprehensive and accurate. In addition, information can help parents to be more pragmatic in their expectations of themselves and their children, and in so doing, are more likely to act in developmentally appropriate ways with their children (Bornstein et al., 2003).

Further research on support indicates that families who receive strong social support are better placed to handle challenges more effectively (Dunst \& Trivette, 1994). However, the current study revealed that parenting a child with hearing loss can be a very lonely experience, especially when it is done by 
a single parent, or with no support from family members. Our findings are consistent with studies conducted by Lederberg and Golbach (2002) and Jackson et al. (2010) that have shown that parents experience social isolation and loneliness when parenting a child with hearing loss. Some family members, or even one parent, may distance themselves in reaction to their fears about the disability, leaving one parent or family member alone with the caregiving responsibility. Some families may struggle to accept a child's hearing loss based on their preconceived beliefs about disability (Marschark \& Seligman, 1993). A parent's view of disability may see them experiencing a personal conflict between their beliefs about a disability and having a child with a disability. Stigmatization and stereotyping still exists today, adding to the exclusion and isolation of parents, children with disabilities, and even families. Our study found that mothers in particular experienced isolation, stigmatization, and blame from family members, diminishing their sense of communion and community (McDaniel \& Pisani, 2012).

The findings also highlighted recommendations made by parents for social support groups to meet other parents who experience the same challenges as them. Connecting with other parents with similar experiences can empower parents and build their confidence. Creating and supporting opportunities to bring parents together helps them form their own support communities. These findings are analogous to the findings of Henderson (2015), Jackson (2011), Jackson et al. (2008), and Friedman Narr and Kemmery (2015), which advocate for the needs of parents to be met via programs, such as parent-toparent support, or parent mentor programs.

Findings from our study concur with Decker et al. (2012) and Porter and Edirippulige (2007) that parents are searching for alternative ways of obtaining professional support, for example, via the social media (Internet and WhatsApp) platform. This area of support for parents needs further exploration, especially in terms of seeking the correct information that may be parent, child, and family-specific. These findings propose a further exploration of the effective use of such formal and informal support for parents and with professionals, which includes the exploration of ethical boundaries for professionals.

The participants' narratives in the interviews elucidated how parents' experience and interpret the social reality-based challenges they experience when parenting a child with hearing loss. A strength of this study was the diversity of parents that participated in the research, as participants were parents of children who attended different schooling systems (oral and signed), and used different amplification (hearing aids and cochlear implants). However, the sample size poses a limitation and it, therefore, cannot be assumed that the findings of the study are representative of all parents' experiences when parenting a child with hearing loss. 


\section{Implications for practice}

South Africa has a strong legal and policy framework around which preventative interventions are discussed. The legal and policy framework as mandated by Chapter 8 of the Children's Amendment Act (Act No. 41 of 2007) sets out preventative and early intervention measures to support and develop positive parenting. Section 144, in particular, focuses on developing and improving the parental capacity of parents to act in the best interest of their child Taking into consideration that hearing parents might not know much if anything about hearing loss, the current study makes a significant contribution by (1) highlighting the kinds of challenges and social needs experienced by parents, and (2) providing insight into possible interventions that can be offered by government for parents parenting children with a hearing loss. For example, implications for practice would suggest that practitioners, such as social workers working within the disability field, more specifically within deafness, understand the challenges experienced by parents, and work to promote multidisciplinary practices and collaboration. Multidisciplinary practices and collaboration are usually drawn from the fields of social work, audiologists, deaf professionals, intervention program leaders, parent mentors, and researchers who should be trained and involved in local communities of the deaf. Part of these collaborative services provided to parents should include parent social and emotional support, where parents are connected to support systems so that they can receive the necessary information, knowledge, and understanding that can enable them to function effectively as parents, as well as promote the well-being of parents and family (Moeller et al., 2013). For example, part of social work services may include a parent support group intervention model that would assist parents in managing their difficulties of parenting a child with hearing loss. A parent-to-parent support group thus creates an environment of shared information, where parents can learn about communication options, best practice, new research, technological advancements, and amplification options (Henderson, 2015). Based on this research study, deaf mentor programs too can be offered to parents. These mentor programs can assist parents and families in understanding their child's journey and introduce mentors who act as role models for parents who have walked or are walking the same journey.

Moreover, the influence of information, particularly from health and family practitioners, has been acknowledged (Eleweke \& Rodda, 2000). Practitioners can assist parents to gain the necessary information and knowledge so that parents can make informed decisions that are beneficial for them and their family (Moeller et al., 2013). Information provided by health and family practitioners can allay hearing parents' feelings of fear and guilt and promote acceptance of their child with a hearing loss. Practitioners can provide parents and families with the etiology, for example, of their child's hearing loss, 
facilitating a shift from a "fix what is wrong" to "build what is strong" perspective (Duckworth et al., 2005, p. 3).

Similarly, computer and Internet technology can be beneficial to parents in order to access online information and support. This would include building a network of formal and informal parent support via the social media platform (e.g., Facebook, and WhatsApp). Formal support allows parents to connect and communicate with professionals in the field of deafness who can provide parents with unbiased information. Social media also allows parents to connect with other parents, reinforcing mutual support amongst each other.

However, putting in place good, strong interventions requires an awareness of the context in which these parents live. For example, the following factors should be taken into account within the South African context when rendering services to parents: socio-economic status of most parents, diverse cultural backgrounds of parents, parent involvement, poverty, geographical spacing (urban and rural settlements that are far from services), and single parents raising a child with hearing loss. These considerations can have an impact when linking parents to relevant services, parenting programs, and where necessary, for expert intervention.

Furthermore, this study holds scholarly significance for those within the larger disability field and within the field of social work, these findings may stimulate additional explorations of deaf adults' experiences of being parented by hearing parents, or explore how families from diverse cultures process their journey raising a child with hearing loss, thus adding to the suggestions for training and documenting support provided to parents.

\section{Conclusion}

Overall, our findings highlight the challenges that contribute to the experiences of hearing parents parenting children with a hearing loss. They provide an understanding of the complexities of these challenges and emphasize the need for parent and family interventions. They underscore the importance of the multidimensionality of support for parents and contribute to the development of interventions that are aimed at addressing the diverse needs of parents. This research draws upon some international principles relating to the "Best Practice in Family-Centred Early Intervention for Children who are Deaf or Hard of Hearing," which set out to promote the implementation of endorsed evidencedbased principles for family-centered intervention with families and children with hearing loss (Moeller et al., 2013).

\section{Acknowledgments}

We would like to thank all of the parents who willingly shared their experiences with us. 


\section{Disclosure statement}

The authors declare that they have no financial or personal relationships that may have inappropriately influenced them in writing this article.

\section{Funding}

No funding for the study was received.

\section{References}

Asberg, K. K., Vogel, J. J., \& Bowers, C. A. (2008). Exploring correlates and predictors of stress in parents of children who are deaf: Implications of perceived social support and mode of communication. Journal of Child and Family Studies, 17(4), 486-499. https://doi.org/10. 1007/s10826-007-9169-7

Babbie, E. R. (2010). The practice of social research (12th ed.). Wadsworth.

Bailey, M. C., Shilling, S., Morris, C., \& Morris, C. (2013). Meeting the information needs of families of children with chronic health conditions. Physical \& Occupational Therapy in Pediatrics, 33(3), 265-270. https://doi.org/10.3109/01942638.2013.799628

BEMROSE, S. (2003). Giving information to parents - Factors to consider. [Online] Available: http://www.deafnessatbirth.org.uk/content2/support/info/02/index.html

Blose, Z. M., \& Joseph, L. N. (2017). The reality of every day communication for a deaf child using sign language in a developing country. African Health Sciences, 17(4), 1149-1159. https://doi.org/10.4314/ahs.v17i4.24

Bornstein, M. H., Hahn, C. S., Suwalsky, J. T., \& Haynes, O. M. (2003). Socioeconomic status, parenting, and child development: The hollingshead four-factor index of social status and the socioeconomic index of occupations. In M. H. Bornstein \& R. H. Bradley (Eds.). Socioeconomic status, parenting, and child development (pp. 29-82). Erlbaum.

Calderon, R. (2000). Parents' involvement in deaf children's education program as a predictor of a child's language, reading and social-emotional development. Journal of Deaf Studies and Deaf Education, 5(2), 140-155. https://doi.org/10.1093/deafed/5.2.140

Cole, E. B., \& Flexer, C. (2015). Children with hearing loss: Developing listening and talking, birth to six. Plural Publishing.

Decker, K. B., Vallotton, C. D., \& Johnson, H. A. (2012). Caregivers' communication decision for children with hearing loss: Sources of information and influence. American Annals of the Deaf, 157(4), 326-339. https://doi.org/10.1353/aad.2012.1631

DesJardin, L. (2016). Avoiding assumptions: Avoiding assumptions: Communication decisions made by hearing parents of deaf children. AMA Journal of Ethics, 18(4), 442-446. https://doi. org/10.1001/journalofethics.2016.18.4.sect1-1604

Duckworth, A. L., Steen, T. A., \& Seligman, M. E. P. (2005). Positive psychology in clinical practice. The Annual Review of Clinical Psychology, 1(1), 629-651. https://doi.org/10.1146/ annurev.clinpsy.1.102803.144154

Dunst, C. J., \& Trivette, C. M. (1994). What is effective helping? In C. J. Dunst, C. M. Trivette, \& A. G. Deal (Eds.). Supporting and strengthening families: Vol. 1. Methods, strategies and practices. (pp. 162-170). Brookline Books.

Eleweke, C. J., \& Rodda, M. (2000, July 24-28). Enhancing inclusive education in developing countries. Paper delivered at the International special education congress. University of Manchester. 
Freeman, B., Dieterich, C., \& Rak, C. (2002). The struggle for language: Perspectives and practices of urban parents with children who are deaf or hard of hearing. American Annals of the Deaf, 147(5), 37-44. https://doi.org/10.1353/aad.2012.0237

Friedman Narr, R., \& Kemmery, M. (2015). The nature of parent support provided by parent mentors for families with deaf/hard-of-hearing children: Voices from the start. The Journal of Deaf Studies and Deaf Education, 20(1), 67-74. https://doi.org/10.1093/deafed/enu029

Gilliver, M., Ching, T., \& Sjahalam-King, J. (2013). When expectation meets experience: Parents' recollections of and experiences with a child diagnosed with hearing loss soon after birth. International Journal of Audiology, 52(Sup 2), S10-S16. https://doi.org/10.3109/ 14992027.2013.825051

Hadjikakou, K., \& Nikolaraozi, M. (2008). The communication experiences of adult deaf people within their family during childhood in Cyprus. Deafness and Education International, 10(2), 60-79. https://doi.org/10.1179/146431508790559823

Hall, M. L., Hall, W. C., \& Caselli, N. K. (2019). Deaf children need language, not (just) speech. First Language, 39(4), 367-395. https://doi.org/10.1177/0142723719834102

Henderson, R., (2015). Parent-to-parent support for parents of deaf or hard of hearing: A conceptual framework. Thesis (MA). University of Western Ontario.

Hintermair, M. (2000). Hearing impairment, social networks, and coping: The need for families with hearing-impaired children to relate to other parents and to hearing-impaired adults. American Annals of the Deaf, 145(1), 41-53. https://doi.org/10.1353/aad.2012.0244

Humphries, T., Kushalnagar, P., Mathur, G., Napoli, D. J., Rathmann, C., \& Smith, S. (2019). Support for parents of deaf children: Common questions and informed, evidence-based answers. International Journal of Paediatric Otorhinolaryngology, 118, 134-142. https://doi. org/10.1016/j.ijporl.2018.12.036

Jackson, C. W. (2011). Family supports and resources for parents of children who are deaf or hard of hearing. American Annals of the Deaf, 156(4), 343-362. https://doi.org/10.1353/aad. 2011.0038

Jackson, C. W., Traub, R. J., \& Turnbull, A. P. (2008). Parents' experiences with childhood deafness: Implications for family-centred services. Communication Disorders Quarterly, 29 (2), 82. https://doi.org/10.1177/1525740108314865

Jackson, C. W., Wegner, C. R., \& Turnbull, A. P. (2010). Family quality of life following early identification of deafness. Language, Speech, and Hearing Services in Schools, 4(2), 194-205. https://doi.org/10.1044/0161-1461(2009/07-0093)

Jamieson, J. R., Zaidman-Zait, A., \& Poon, B. (2011). Family support needs as perceived by parents of preadolescents and adolescents who are deaf or hard of hearing. Deafness \& Education International, 13(3), 110-130. https://doi.org/10.1179/1557069X11Y.0000000005

Joseph, L., \& Alant, E. (2000). Strangers in the House? Communication between Mothers and their hearing impaired children who sign. South African Journal of Communication Disorders, 47(1), 15-24. https://doi.org/10.4102/sajcd.v47i1.218

Klenke, K. (2008). Qualitative research in the study of leadership. Emerald Group Publishing Ltd.

Kobosko, J., \& Zalewska, M. (2011). Maternal identity of hearing mothers of deaf adolescents: Empirical studies - an interpersonal approach. Volta Review, 111(1), 39-59. https://doi.org/ 10.17955/tvr.111.1.655

Kushalnagar, P., Topolski, T., Schick, B., Edwards, T., Skalicky, A., \& Patrick, D. (2011). Mode of communication, perceived level of understanding and perceived quality of life in youth who are deaf or hard-of-hearing. Journal of Deaf Studies and Deaf Education, 16(4), 512-523. https://doi.org/10.1093/deafed/enr015 
Lederberg, A. R., \& Golbach, T. (2002). Parenting stress and social support in hearing mothers of deaf and hearing children: A longitudinal study. Journal of Deaf Studies and Deaf Education, 7(4), 330-345. https://doi.org/10.1093/deafed/7.4.330

Marschark, L., \& Seligman, M. (1993). Counselling persons with disabilities: Theoretical and clinical perspectives. PRO-ED.

Marschark, M. (2007). Raising and educating a deaf child. Oxford University Press.

Mason, A., \& Mason, M. (2007). Psychologic impact of deafness on the child and adolescent. Primary Care: Clinics in Office Practice, 34(2), 407-426. https://doi.org/10.1016/j.pop.2007. 04.003

McDaniel, S., \& Pisani, A. (2012). Family dynamics and caregiving for people with disabilities. In R. C. Talley \& J. E. Crews (Eds.). Multiple dimensions of caregiving and disability: Research, practice, policy. (pp. 11-28). Springer.

McKee, R. (2006). Connecting hearing parents with the deaf world. Sites: A Journal of Social Anthropology and Cultural Studies, 3(1), 143-167. https://doi.org/10.11157/sitesvol3iss1id45

Moeller, M. P., Carr, G., Seaver, L., Stredler-Brown, A., \& Holzinger, D. (2013). Best practices in family-centred early intervention for children who are deaf or hard of hearing: An international consensus statement. The Journal of Deaf Studies and Deaf Education, 18(4), 429-445. https://doi.org/10.1093/deafed/ent034

Munoz-Baell, I. M., \& Ruiz, M. T. (2000). Empowering the deaf. Let the deaf be deaf. Journal of Epidemiology and Community Health, 54(1), 40-44. https://doi.org/10.1136/jech.54.1.40

O'Connor, C., \& Joffe, H. (2020). Intercoder reliability in qualitative research: Debates and practical guidelines. International Journal of Qualitative Methods, 19, 1-13, 160940691989922. https://doi.org/10.1177/1609406919899220

Olin, S. S., Williams, N., Pollock, M., Armusewicz, K., Kutash, K., Glisson, C., \& Hoagwood, K. E. (2014). Quality indicators for family support services and their relationship to organizational social context. Administration and Policy in Mental Health and Mental Health Services Research, 4(1), 43-54. https://doi.org/10.1007/s10488-013-0499-z

Parker, M. J., Fortnum, H. M., Young, I. D., \& Davis, A. C. (2000). Genetics and deafness: What do families want? Journal of Medical Genetics, 37(10), e26-e26. https://doi.org/10.1136/jmg. 37.10.e26

Peterson, R. (2001). Scared to deaf: Language anxiety among ASL students. http://www.flagler. edu/about_f/deafstudies.html

Polit, D. F., \& Beck, C. T. (2012). Nursing research: Principles and methods. Lippincott Williams \& Wilkins.

Porter, S., \& Edirippulige, S. (2007). Parents of deaf children seeking hearing loss related information on the internet: The Australian experience. The Journal of Deaf Studies and Deaf Education, 12(4), 518-529. https://doi.org/10.1093/deafed/enm009

Quittner, A. L., Barker, D. H., Cruz, I., Snell, C., Grimley, M. E., Botteri, M., \& Investigative Team, C. (2010). Parenting stress among parents of deaf and hearing children: Associations with language delays and behavior problems. Parenting, Science and Practice, 10(2), 136-155. https://doi.org/10.1080/15295190903212851

Ramma, L., \& Sebothoma, B. (2016). The prevalence of hearing impairment within the Cape Town Metropolitan area. South African Journal of Communication Disorders, 63(1), a105. https://doi.org/10.4102/sajcd.v63i1.105

Republic of South Africa. (2007). Children's Amendment Act 41 of 2007. In Government Gazette. Government Printer.

Ritchie, J., \& Lewis, J. (2003). Qualitative research practice-a guide for social science students and researchers. Sage.

Statistics South Africa. (2012). Census 2011 release. Pretoria. 
Steinberg, A., Kaimal, G., Ewing, R., Soslow, L. P., Lewis, K. M., Krantz, I., \& Li, Y. (2007). Parental narratives of genetic testing for hearing loss: Audiologic implications for clinical work with children and families. American Journal of Audiology, 16(1), 57-67. https://doi. org/10.1044/1059-0889(2007/005)

Storbeck, C. (2012). Childhood hearing loss in the developing world. https://www.researchgate. net>publication>236633801_Childhood_Hearing

Swanepoel, D., \& Storbeck, C. (2008). EHDI Africa: Advocating for infants with hearing loss in Africa. International Journal of Audiology, 47(1), S1-S2. https://doi.org/10.1080/ 14992020802300912

Swanepoel, D., Storbeck, C., \& Friedland, P. (2009). Early hearing detection and intervention in South Africa. International Journal of Pediatric Otorhinolaryngology, 73(6), 783-786. https:// doi.org/10.1016/j.ijporl.2009.01.007

Szarkowski, A., \& Brice, P. (2016). Hearing parents' appraisals of parenting a deaf or hard-ofhearing child: Application of a positive psychology framework. Journal of Deaf Studies and Deaf Education, 21(3), 249-258. https://doi.org/10.1093/deafed/enw007

Tamis-LeMonda, C. S., Uzgiris, I. C., \& Bornstein, M. H. (2002). Play in parent-child interactions. In M. H. Bornstein (Ed.. Handbook of parenting (2nd), 5,221-241. Erlbaum.

UN-Habitat. (2014). The State of African cities 2014: Re-imagining sustainable urban transitions.

University of the Witwatersrand. (2019). Hi-Hopes. https://www.wits.ac.za/hi-hopes/

West, D. (2012). Signs of hope deaf hearing family life. Cambridge Scholar Publishing.

Young, A. (2002). Factors affecting communication choice in the first year of life: Assessing and understanding an on-going experience. Deafness and Education International, 4(1), 2-11. https://doi.org/10.1179/146431502790560935

Young, A., Hunt, R., Hall, A., McCracken, W., Skipp, A., \& Tattersall, H. (2005). Informed Choice and Deaf Children: Underpinning Concepts and Enduring Challenges. The Journal of Deaf Studies and Deaf Education, 11(3): 322-336. https://doi.org/10.1093/deafed/enj041

Young, A. M. (2003). Parenting and deaf children - A psycho-social literature-based framework. National Deaf Children's Society.

Zaidman-Zait, A. (2007). Parenting a child with a cochlear implant: A critical incident study. Journal of Deaf Studies and Deaf Education, 12(2), 221-241. https://doi.org/10.1093/deafed/ enl032

Zaidman-Zait, A., \& Jamieson, J. (2004). Searching for Cochlear implant information on the internet maze: Implications for parents and professionals. Journal of Deaf Studies and Deaf Education, 9(4), 413-426. https://doi.org/10.1093/deafed/enh046

Zaidman-Zait, A., \& Most, T. (2005). Cochlear implants in children with hearing loss: Maternal expectations and impact on the family. Volta Review, 105, 129-150. https://psycnet.apa.org/ record/2008-06402-004 